\title{
Provision of Sustainable Water Supply System in Nigeria: A Case Study of Wannune-Benue State
}

\author{
D. M. Akali", O. T. Iorhemen, Otun J. A., Alfa M. I \\ Department of Water Resources \& Environ. Engineering, Ahmadu Bello University, Zaria, Nigeria \\ *Corresponding author: akalimartins@yahoo.com \\ Received December 23, 2013; Revised January 05, 2014; Accepted January 20, 2014
}

\begin{abstract}
It has been estimated that about 80 percent of all the diseases in the developing countries are related to unsafe water supply and inadequate sanitation. Lack of access to improved sanitation and safe water [1] supply is a global crisis. The effects of inadequate water supply are more visible and prevalent in Sub-Saharan Africa. This paper presents an assessment of the existing water supply system at Wannune-Nigeria based on an onsite-physical inspection and discussion with some stakeholders. The assessment revealed that the existing water supply systems broke down due to poor and/or lack of proper operation and maintenance practice. This led to the dependence by residents on water from unprotected wells, rivers and streams. This is capable of causing some sanitation and water related diseases like cholera, diarrhea, among others. To improve the situation, a provisional design of a water supply system for Wannune was done. The system comprises a water treatment plant of $5,000 \mathrm{~m}^{3} / \mathrm{d}$ capacity, transmission mains of 41,000 metres length and three elevated reservoirs of 200, 500 and $1000 \mathrm{~m}^{3}$ capacities for storage and transmission of the treated water.
\end{abstract}

Keywords: water treatment plant, Wannune, diseases, water supply system, sanitation

Cite This Article: D. M. Akali, O. T. Iorhemen, Otun J. A., and Alfa M. I, "Provision of Sustainable Water Supply System in Nigeria: A Case Study of Wannune-Benue State.” World Journal of Environmental Engineering, vol 2, no. 1 (2014): 1-5. doi: 10.12691/wjee-2-1-1.

\section{Introduction}

Water is one of the world's most valuable resources. It is a basic necessity of life for both plants and animals. Mankind cannot, in fact, survive without water as even the human body is made up of about $70 \%$ water [1]. Water resources are becoming increasingly scarce in many parts of the world due to development, increased demand [2], climate change and resulting drought and explosive population growth. The availability of a reliable and clean supply of water is one of the most important determinants of our health [3]. According to WHO, diseases related to drinking-water contamination represent a major burden on human health and the interventions to improve the quality of drinking-water provide significant benefits to health [4]. The water crises of the world are not about having too little water to satisfy our needs. It is a crisis of managing water so badly that billions of people and the environment suffer badly [5].

The Federal Ministry of Water Resources Roadmap for Nigeria Water Sector (2011) estimates the water resources potential of the country as 267 and 92 billion $\mathrm{m}^{3}$ of surface and ground water respectively [6]. It also estimates the water supply and sanitation service coverage as $58 \%$ (87 million) and $32 \%$ (54 million) respectively. Unicef estimates are slightly lower at $47 \%$ water supply service coverage. It has also been estimated that about $60 \%$ of all the diseases in the developing countries are

related to unsafe water supply and inadequate sanitation $[6,7]$.

About 51\% of Nigeria's 165 million population resides in rural or remote areas [8] and only $47 \%$ of this rural populace have access to improved water sources [9]. Of the $49 \%$ that live in urban and peri-urban areas, only $72 \%$ of have access to improved water sources [9].

Water supply is a basic requirement of life [10]. It is essential to sustain life, and a satisfactory (adequate, safe and accessible) supply must be available to all [4]. The availability of a reliable and clean supply of water is one of the most important determinants of our health [3]. Water scarcity poses risks and stress for human society [11]. The World Health Organisation (WHO) identifies improvement in access to safe drinking-water as a contributing factor to tangible benefits to health [10].

The provision of water supply systems in the region is thus, important and urgent, requiring the use of existing, emerging and innovative technologies that are also sustainable.

This research aimed at assessing the existing water supply situation in Wannune, Benue Sate, Nigeria. The scope extended to providing designs of suitable water supply systems that would help in addressing the existing water supply problems.

\section{Materials and Methods}


The method adopted in this study is based on: Existing System Assessment and Provisional design of water supply system.

\subsection{Description of Study Area}

Wannune is the administrative headquarters of Tarka Local Government Area of Benue Sate (Figure 1). It is a small town with an area of $371 \mathrm{~km}^{2}$ and a population 79,494 , based on the census of 2006 [12]. Tarka LGA of Benue State is situated in a rural setting, and the major occupation of the people is farming. Few are either employed in white-collar jobs or are involved in private businesses.

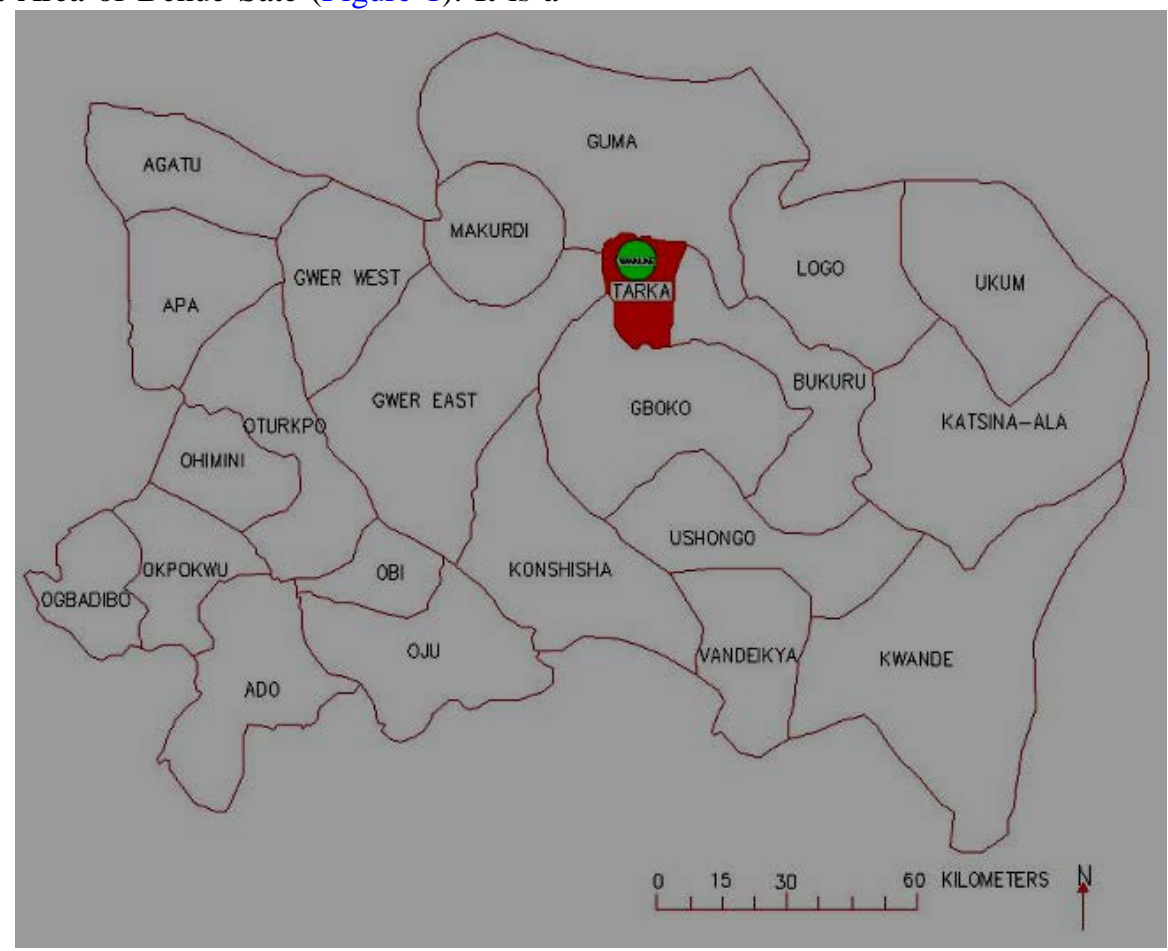

Figure 1. Map of Benue State showing the study area

\subsection{Existing System Assessment}

On-site physical survey was carried out to assess the existing water supply system at Wannune. Digital camera (Model: Power Shot A495) was used to capture abandoned water treatment plant (Figure 2), Wannune Dam (Figure 3) and existing elevated tanks (Figure 4) respectively. Interviews were also conducted with some staff of Benue State Water Board and Ministry of Water Resources. Global Positioning System (GPS) was then used to locate the position of the dam, proposed water treatment plant and elevation tanks.
The population for 2006 census was obtained and used to project the present population of Wannune to the year 2012 using geometrical projection method (equation 1).

$$
P_{f}=P_{i}(1+r / 100)^{n}
$$

Where,

$\mathrm{P}_{f}=$ Final projected population,

$\mathrm{P}_{i}=$ Original population before projection,

$r=$ growth rate,

$\mathrm{n}=$ Interval (in years)

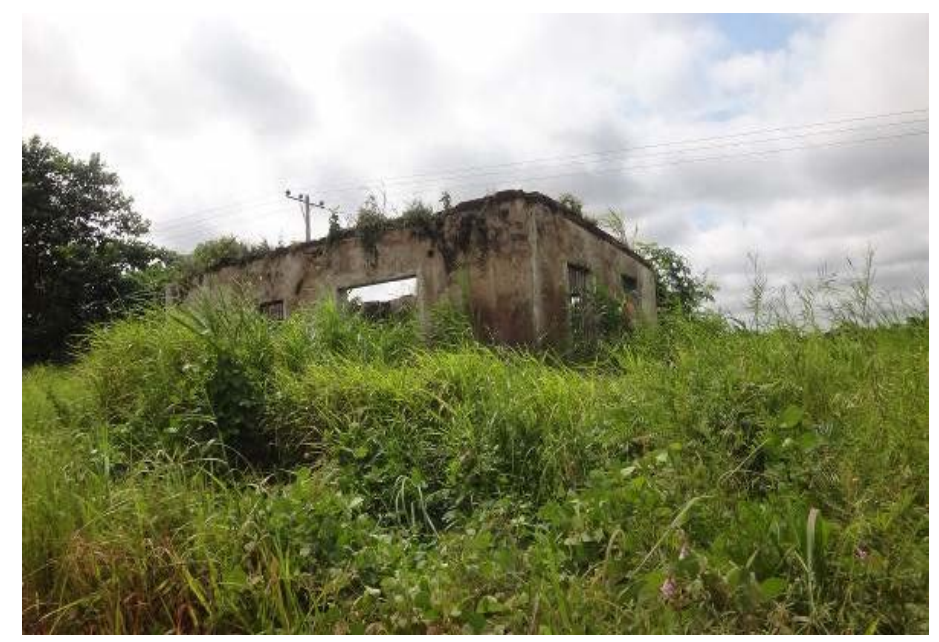

Figure 2. Abandoned Water Treatment Plant 


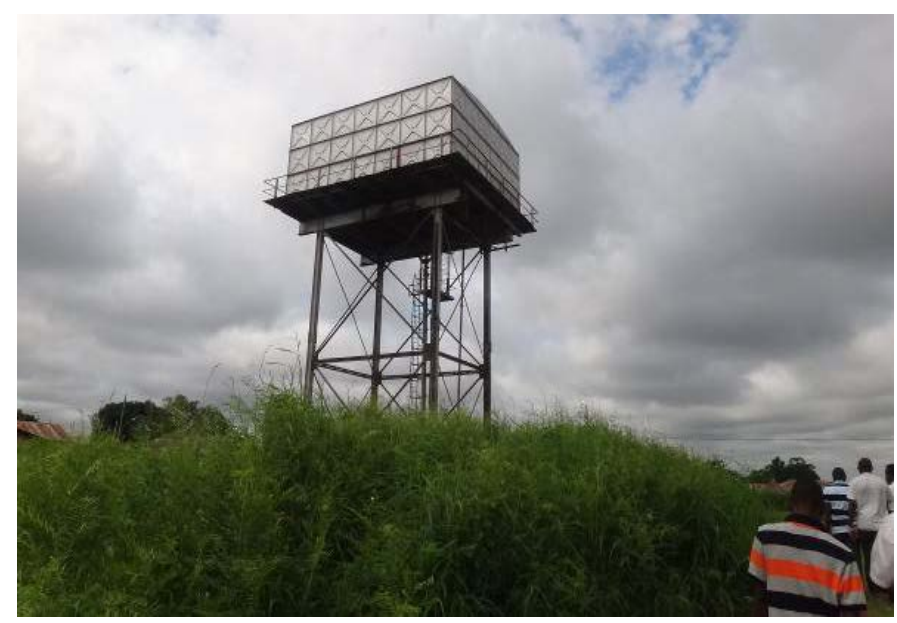

Figure 3. Existing elevated water tank

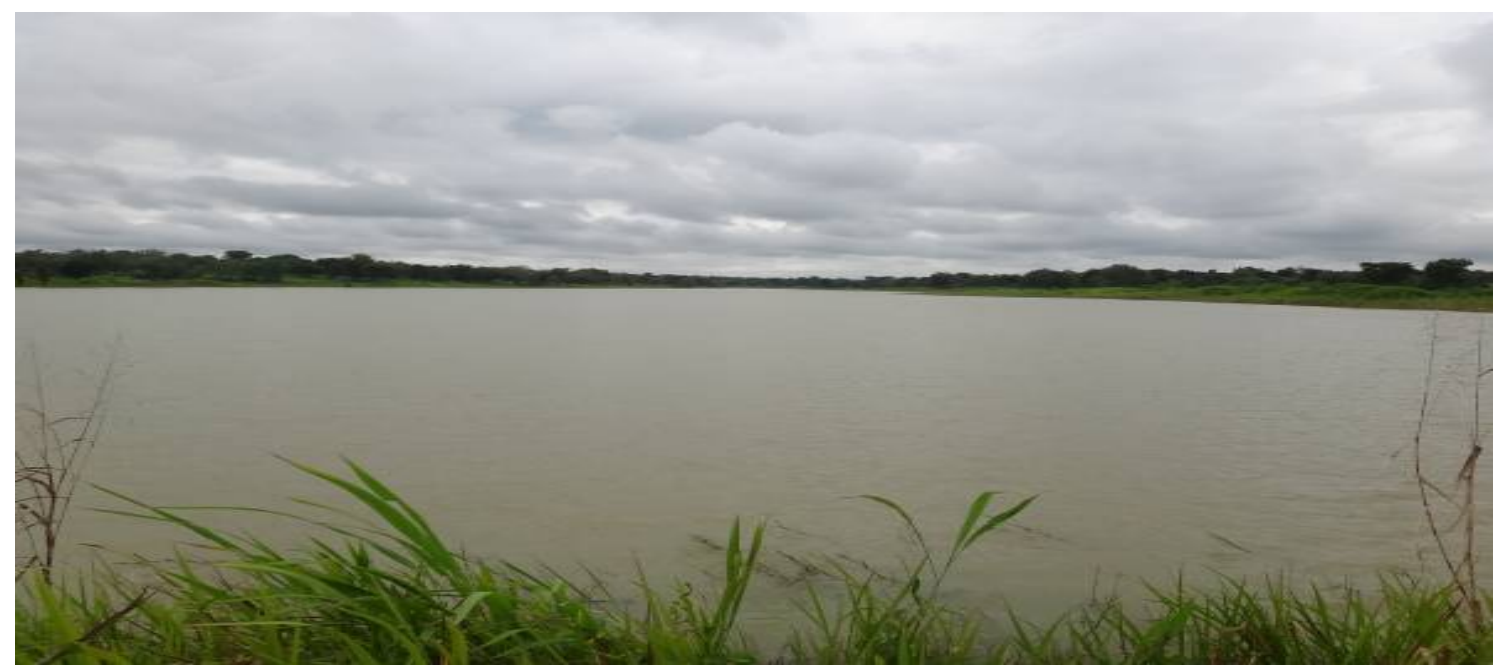

Figure 4. Existing Dam Reservoir at Wannune

\subsection{Design of Water Supply System for Wannune}

The main unit operations of a water treatment plant include the aeration unit, coagulation and flocculation unit, sedimentation unit, filtration unit, storage and disinfection unit. Every unit operation aims at removing or reducing contaminants to the desired degree in order to conform to available standards (the Nigerian Standard for Drinking Water Quality and the WHO guidelines). The design of the various hydraulic units was carried out using the determined maximum daily demand.

\section{Results and Analysis}

The results of findings for the research are presented in two categories: Engineering assessment of the existing water supply systems and Provisional design of sustainable water supply system for Wannune.

\subsection{Engineering Assessment of the Existing Water Supply Systems}

At present, there is no provision for potable water supply at Wannune. Majority of the households depend on ground water from boreholes but are always faced with the problem of frequent breakdown. Other houses that are far from such boreholes obtain their water from streams and rivers around the Wannune village. It was gathered that there used to be ground water treatment plant at Annune-Ikpa Road at Wannune town but was later abandoned due to frequent breakdown and lack of skilled operation and maintenance staff to always repair the boreholes when faulty. As a result, the plant facilities have deteriorated.

Also, some of the facilities have been stolen while some have collapsed completely. The only water supply system seen during the on-site survey carried out was the existing $200 \mathrm{~m}^{3}$ steel overhead tank located at the George Akume Library and Computer Centre. Even the existing tank is faced with a lot of corrosion attacks and leakages problem. This situation has made the residents to majorly depend on water from rivers. However, the continuous dependence on such untreated water is poses a great risk of disease outbreak such as typhoid, cholera, diarrhea etc. There is therefore the need to construct a water treatment plant at the Wannune town to tap water from the existing Wannune earth dam which derives its source from River Mchiilla.

\subsection{Provisional Design of Sustainable Water Supply System for Wannune Environs}


The total average population of Wannune was estimated at 93,983.88 persons. Using an average daily water consumption of 80 litre/capita/day, the estimated population was used to determine the treatment plant capacity of Wannune water treatment plant.

Thus:

Plant Capacity, $\mathrm{Q}=5,000 \mathrm{~m}^{3} /$ day.

The flow rate was used in designing the various hydraulic units of the treatment plant: raw water intake, flocculation and coagulation tank, sedimentation unit, filtration unit, chlorination plant and clear water tank.

\subsubsection{Design of Transmission Mains}

Following the design of water treatment plant of 5,000 $\mathrm{m}^{3} /$ day capacity for Wannune, the transmission mains and distribution networks were designed using hydraulic calculation equation formulae for flow and HazenWilliams equation.

Thus:

$$
Q=A \times V
$$

Where:

$A=$ Area in square metres $\left(\mathrm{m}^{2}\right)$, and

$\mathrm{V}=$ Velocity in $\mathrm{m} / \mathrm{s}$

Head loss,

$$
h_{l}=i \times L
$$

where

$\mathrm{I}=$ Gradient

$\mathrm{L}=$ Length in $\mathrm{m}$

$$
i=\frac{10.67^{1.852}}{C_{h}^{1.852} d_{i}^{4.87}}
$$

Where

$\mathrm{Q}=$ flow in $\mathrm{m}^{3} / \mathrm{s}$

$\mathrm{C}_{\mathrm{h}}=$ Modulus of Hazen-Williams

$\mathrm{d}_{\mathrm{i}}=$ Diameter of Pipes in $\mathrm{m}$

Hence, the proposed pipe sizes as calculated are presented in Table 1 below. Table 2 shows the proposed

\begin{tabular}{|c|c|c|c|c|}
\hline S/No & Pipe Size (mm) & & ) & Material \\
\hline 1 & DN300 & \multicolumn{2}{|c|}{250} & DI \\
\hline 2 & DN250 & \multicolumn{2}{|c|}{6190} & DI \\
\hline 3 & DN200 & \multicolumn{2}{|c|}{950} & DI \\
\hline 4 & DN150 & \multicolumn{2}{|c|}{440} & DI \\
\hline 5 & DN200 & \multicolumn{2}{|c|}{950} & PVC \\
\hline 6 & DN150 & \multirow{2}{*}{\multicolumn{2}{|c|}{$\begin{array}{l}11387 \\
20550\end{array}$}} & PVC \\
\hline 7 & DN100 & & & PVC \\
\hline & \multirow{2}{*}{ TOTAL } & DI & 7,830 & \multirow{2}{*}{$40,717 \mathrm{~m}$} \\
\hline & & PVC & 32,887 & \\
\hline
\end{tabular}
reservoirs with their location.

Table 1. Summary of Proposed Transmission Mains and Distribution lines at Wannune

Table 2. Summary of Proposed Reservoir Tanks at Wannune

\begin{tabular}{|c|c|c|c|}
\hline S/No & Reservoir Capacity $\mathbf{( m}^{\mathbf{3}} \mathbf{)}$ & Location & Remark \\
\hline 1 & 1000 & New Concrete Tank & Concrete Reservoir \\
\hline 2 & 500 & LGA Secretariat & Steel Elevated Water Tank \\
\hline 3 & 200 & Library and Computer Centre & Rehabilitation of Existing Head Tank \\
\hline
\end{tabular}

The proposed pipe layout is shown in Figure 5 below.

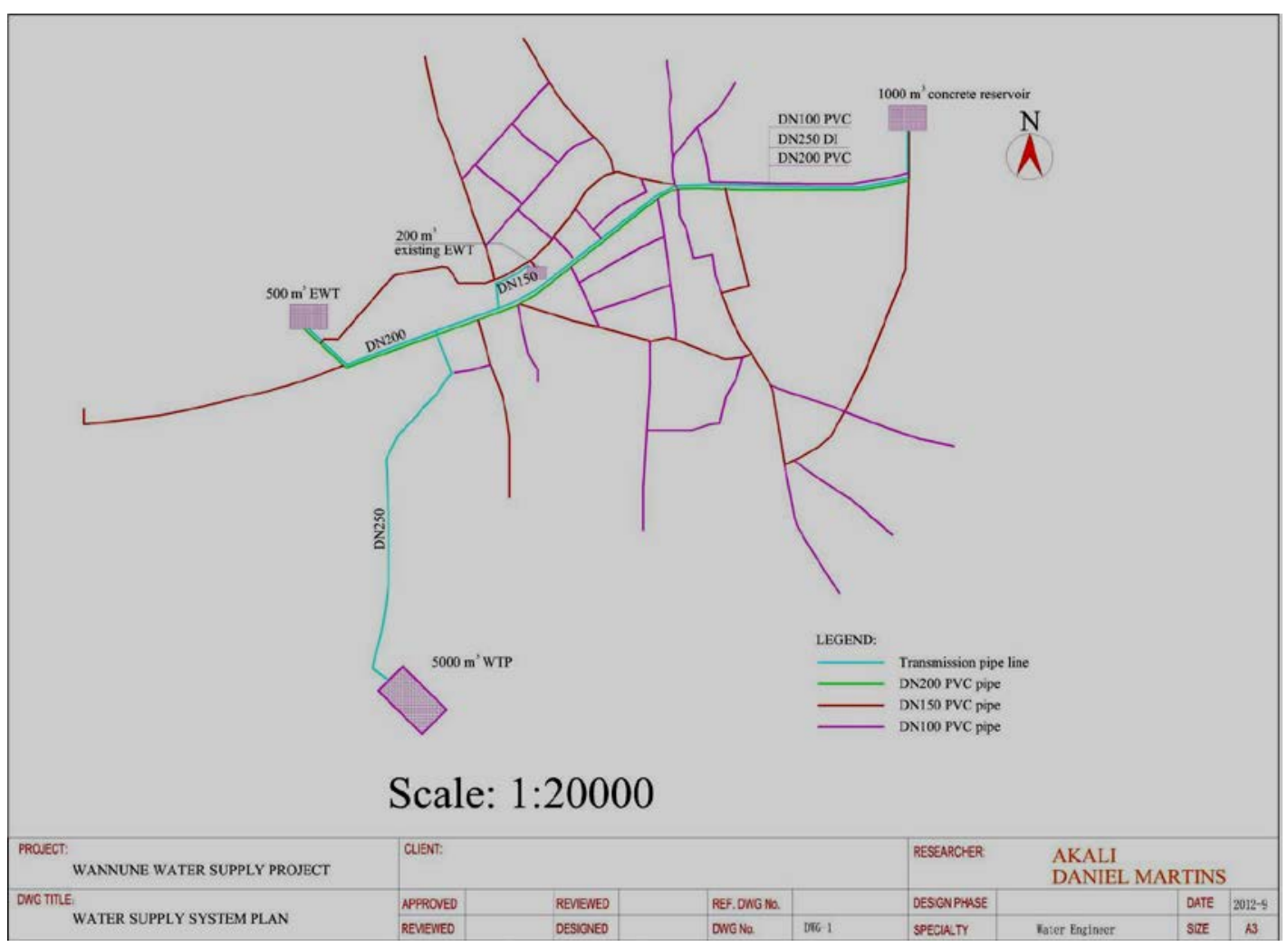

Figure 5. Pipeline Layout for the Transmission and Distribution Network at Wannune 


\section{Conclusions}

The physical assessment of the water supply system at Wannune has shown that lack and/or poor operation and maintenance led to the breakdown of systems. The situation has led to the dependence of the residents on unreliable wells, untreated water from rivers and streams. This puts them at a risk of an epidemic from water-related and/or excreta related diseases.

In order to ameliorate the system, a water treatment plant of capacity $5,000 \mathrm{~m}^{3} / \mathrm{d}$ was designed for Wannune and environs based on the population.

The water source would be the existing Dam reservoir at Wannune. In addition to the water treatment plant design, the transmission mains and distribution networks for the conveyance of the treated water to the entire study area were designed. This would cover about 41 kilometres total length.

The designed water treatment plant, would help in the provision of sustainable water supply to Wannune which in turn would help in achieving part of the millennium development goals of reducing infant mortality rate as well as ensuring environmental sustainability.

\section{References}

[1] Tebbutt, T.H.Y., Principles of water quality control, ButterWorthHeinemann, Boston, 1998.
[2] Pearce, G.K., "UF/MF pre-treatment to RO in seawater and wastewater reuse applications: a comparison of energy costs", Desalination, 222 (1-3). 66-73. 2008.

[3] Parsons, S.A. and Jefferson, B., Introduction to potable water treatment processes, Blackwell Pub, Oxford, 2006.

[4] WHO Guidelines for Drinking-water Quality, FIRST ADDENDUM TO THIRD EDITION, Volume 1 Recommendations, World Health Organisation, Geneva, 2008.

[5] Ali, A.K., Development of Water Infrastructure in Nigeria: Challenges and Prospects, in Meeting of the Nigeria Society of Engineers. 2012.

[6] Prüss-Üstün, A., Kay, D., Fewtrell, L., and Bartram, J., "Unsafe water, sanitation and hygiene", in Comparative Quantification of Health Risks: Global and Regional Burden of Disease due to Selected Major Risk Factors, Majid Ezzati, Lopez, A.D., Rodgers, A., and Murray, C.J.L., Editors. Geneva, World Health Organization, 2004

[7] Akali, D.M., Iorhemen, O.T., and Adie, D.B., "Comparative Analysis on the Use of Septic Tank and Sanitary Sewerage Systems at Malali Housing Estate, Kaduna-Nigeria", International Journal of Engineering Research \& Technology (IJERT), 1 (09). 2012.

[8] Ohunakin, O.S., Adaramola, M.S., Oyewola, O.M., and Fagbenle, R.O., "Generation of a typical meteorological year for north-east, Nigeria", Applied Energy, 112 (0). 152-159. 2013.

[9] Onabolu, B., Jimoh, O.D., Igboro, S.B., Sridhar, M.K.C., Onyilo, G., Gege, A., and Ilya, R., "Source to point of use drinking water changes and knowledge, attitude and practices in Katsina State, Northern Nigeria", Physics and Chemistry of the Earth Parts A/B/C, 36 (15-15). 1189-1196. 2011.

[10] Mara, D.D. and Evans, B., Sanitation and Water Supply in Lowincome Countries, Duncan Mara, Barbara Evans \& Ventus Publishing ApS, 2011.

[11] Adeniji-Oloukoi, G., Urmilla, B., and Vadi, M., "Households' coping strategies for climate variability related water shortages in Oke-Ogun region, Nigeria", Environmental Development, 5 (0). 23-38. 2013.

[12] NPC, Official Records of the 2006 Census. Natonal Population Commission, Nigeria, Abuja, 2007. 